\title{
RANGE EXTENSION AND SOLITARY NEST FOUNDING IN POLISTES EXCLAMANS (HYMENOPTERA: VESPIDAE)*
}

\author{
By Mary Jane West \\ Museum of Comparative Zoology, Harvard University
}

It is generally difficult to document temporal changes in the geographic distribution of insect species because of the sporadic nature of collections made primarily for taxonomic study and specimen identification. Therefore some new distribution data providing an unusual amount of evidence for range extension in the social wasp Polistes exclamans Viereck seem of interest. Several states have been added to the known range of $P$. exclamans in the last twenty years; and $P$. exclamans is now abundant in east-central Missouri, where it was almost certainly absent two decades ago. Solitary nest founding by $P$. exclamans queens may enhance the ability of this species to colonize new areas.

Porter (1963) first suggested that $P$. exclamans may be extending its range. He reported new records from Maryland and New Jersey, noting that these states are considerably north of the northernmost previous records for $P$. exclamans in the Atlantic Coast states.

A collecting trip to St. Louis and Jefferson Counties, Missouri, in July, 1967, provided the first evidence of range extension by Polistes exclamans in the midwestern United States. The purpose of the trip was to collect specimens of Polistes species observed by the Missouri naturalist Phil Rau prior to his death in 1948. Rau repeatedly mentioned (e.g., in Rau I929, I942a, I942b) that only four species of Polistes existed in Missouri: P. pallipes (= metricus), $P$. rubiginosus, $P$. annularis, and $P$. variatus (= fuscatus) (Rau's determinations by $\mathrm{J}$. Bequaert). However, I found $P$. exclamans nests common in barns and abandoned buildings in southern St. Louis County, and collected specimens of $P$. exclamans in six of the eight localities where Polistes wasps were found (other species collected were $P$. metricus, $P$. fuscatus, and $P$. rubiginosus). Three of the $1967 P$. exclamans localities were frequented by Rau during his studies of Polistes: "Meramac Highlands", an area near the Meramac River about eight miles southwest of St. Louis (first mentioned in Rau and Rau, I918) ; Kirkwood, Rau's home town for 24 years (first mentioned as a study locality in Rau, I94I); and a farm near

*Manuscript received by the editor 17 June 1968 
the present Beaumont Reservation, I 8 miles southwest of St. Louis, the former site of some "woodcutters' cabins" often visited by Rau during the years 1945-1947 (Rau, unpublished manuscript). ${ }^{1}$

There is little doubt that Rau would have noticed and reported $P$. exclamans in the St. Louis region if the species had been present there during his lifetime. He published 39 papers and one book chapter (Rau and Rau, I9I8) on the Polistes of 43 named localities in that area during the years 1918-1946, and devoted his last years to writing a book dealing exclusively with the bionomics of Polistes (Rau, unpublished manuscript). Furthermore, Rau would have been unlikely to confuse exclamans with any of the Missouri species he recognized, since it has a distinctive appearance and nest form appreciated and described by Rau when he collected it in Texas (Rau, I943). Therefore it seems reasonable to conclude that the present abundance of Polistes exclamans in southern St. Louis County, Missouri, is due to colonization in that area during the last twenty years.

Examination of museum collections (see Acknowledgments) has revealed specimens of $P$. exclamans from nine states not considered part of the species range in 195I (Bohart, I95 I) (Table I). Eight of the new state records are in the northeastern quarter of the species range, suggesting a generally northward expansion in the eastern half of the United States. Since climate-related range fluctuations are quite common in animals, and there are numerous examples of northward expansion in North America during the present century (see Mayr, 1963), climatic change and/or adaptation to more northern habitats must be considered as possible contributing factors in the expansion of $P$. exclamans. However, there are pre-1950 records of $P$. exclamans from northern Kansas, Nebraska, and Iowa - north of all the new records (Table I) - suggesting that the expansion may not bear a simple relationship to climate.

A possible behavioral basis for range expansion in P. exclamans was suggested by field observations of newly founded Polistes colonies on and near the University of Oklahoma Biological Station (Marshall County, Oklahoma). Nests of $P$. annularis, $P$. apachus, $P$. fuscatus, $P$. metricus and $P$. rubiginosus observed between 20 April and I I May, 1966, were commonly attended by more than one female (foundress). However, each except one of more than Ioo $P$. exclamans colonies was attended by a single female; the one exception had only two foundresses. Solitary nest founding ${ }^{2}$ predominated even

\footnotetext{
${ }^{1}$ Phil Rau's son, Mr. David Rau, kindly helped in locating these sites.

${ }^{2}$ I prefer this term to the older "haplometrosis" or "monogyny", and the term "social nest founding" to "pleometrosis" or "polygyny", for reasons given in West, 1967b.
} 
Table 1

New state records of Polistes exclamans Viereck.

\begin{tabular}{|c|c|c|c|}
\hline State & Locality & Date & Collection \\
\hline Illinois ${ }^{1}$ & Williamson Co. & 1958 & Southern Illinois Univ. ${ }^{2}$ \\
\hline \multirow[t]{3}{*}{ Indiana } & Posey Co. & 1958 & Purdue Univ. \\
\hline & Perry Co. & 1960 & \\
\hline & Floyd Co. & 1965 & \\
\hline \multirow[t]{2}{*}{ Kentucky } & Nelson Co. & 1957 & Purdue Univ. \\
\hline & Bardstown & 1958 & " " " \\
\hline \multirow[t]{5}{*}{ Maryland } & $\underset{\prime \prime}{\text { Prince George Co. }}$ & 1958 & Univ. of Maryland \\
\hline & Public Landing & 1959 & $\begin{array}{l}\text { Los Angeles County } \\
\text { Cornell Univ. }\end{array}$ \\
\hline & Plummers Island & 1961 & " " " \\
\hline & Salisbury & 1960 & see Porter, 1963 \\
\hline & Cambridge & 1960 & \\
\hline \multirow[t]{3}{*}{ Missouri $^{1}$} & Columbia & 1966 & Univ. of Calif. Davis \\
\hline & Boone Co. & $1966-7$ & Univ. of Missouri \\
\hline & St. Louis Co., Jackson Co. & 1967 & Mus. of Compar. Zool. \\
\hline \multirow[t]{3}{*}{ New Jersey } & Penn State Forest & 1955 & see Porter, 1963 \\
\hline & Lebanon State Forest & 1955 & \\
\hline & Metuchen & 1960 & " $" \quad "$ \\
\hline \multirow[t]{2}{*}{ New Mexico } & Eddy Co. & 1956 & Cornell Univ. \\
\hline & Roswell & 1956 & Purdue Univ. \\
\hline Tennessee & Benton Co. & 1953 & Los Angeles County Mus. \\
\hline \multirow[t]{2}{*}{ Virginia } & Gloucester & 1959 & Univ. of Maryland \\
\hline & $\begin{array}{l}\text { Eagle Rock } \\
\text { York Co. }\end{array}$ & $\begin{array}{l}1961 \\
1962\end{array}$ & $\underset{\prime \prime}{\text { Los Angeles County }}$ Mus. $_{\|}$ \\
\hline
\end{tabular}

at "popular" nesting sites: eighteen single-foundress exclamans colonies located in close proximity beneath the porch roof of a small abandoned cottage were dispersed, rather than clustered, beneath the shelter. Furthermore, $P$. exclamans was the only Polistes species among the six common in the area to occupy artificial nesting places erected at the Biological Station on I April - the species was exceptional in colonizing these newly available sites. Eickwort (in

\footnotetext{
${ }^{1}$ The collection of the Illinois Natural History Survey contains 15 specimens of $P$. exclamans from Macoupin Co. Illinois for the years 18901910 , and the University of Missouri collection contains one specimen recorded from Boone Co., Missouri, 1940. However, these states are listed as "new records" here because they were not included in Bohart, 1951, and because of the paucity of $P$. exclamans in early collections from these areas. ${ }^{2}$ collection examined by R. M. Bohart.
} 
press) reports that solitary nest founding also predominates in Kansas populations of $P$. exclamans.

These associated tendencies of $P$. exclamans foundresses to disperse and to move into newly available nesting sites would promote range expansion. In contrast, social foundresses tend to remain and reproduce near their place of origin. In Polistes fuscatus and P. canadensis, foundress associations are composed of siblings which begin new colonies near the parental nest site (West, I967a), and there is indirect evidence that this occurs in other species having social nest founding (see Hamilton, I964; West, I967a).

The mode of nest founding of $P$. exclamans within the newly occupied portions of its range is unknown. While most foundresses were solitary in the populations of $P$. exclamans observed in Oklahoma and Kansas (above), the same species commonly exhibits social nest founding in Texas (Rau, I943; Caskey, I955). Similarly, Rau ( I942b) found only solitary foundresses in $P$. fuscatus ( = "variatus") in Missouri, whereas in Michigan social nest founding was most common in that species (West, I967a, b). Geographic variation in mode of nest founding has also been noted in the European wasp $P$. gallicus (see Hamilton, I964). Thus, while it has been traditional in the literature on social wasps (e.g., Wheeler, 1922) to regard mode of nest founding as a constant feature of a species, it is probably better to consider most Polistes "polyethic" in this respect, with mean size of foundress group differing from locality to locality and from year to year. Various factors, including parasitization (Eickwort, in press), nest site availability, number of overwintering siblings, and dominance relations among foundresses, may affect the frequency of solitary nest founding and the size of foundress groups (see West, r967a). As the observations of this study suggest, solitary nest founding might be expected to increase in frequency in areas where there is opportunity for (and advantage in) expansion; and the ability of some Polistes species to colonize new sites might be limited or delayed by selection for social nest founding.

\section{ACKNOWLEDGMents}

Distribution data from labels of determined specimens of $P$. exclamans were sent to me by entomologists at the following institutions: United States National Museum (A. Menke); University of California, Davis (R. M. Bohart); University of Kansas (G. W. Byers) ; Kansas State University (H. D. Blocker) ; Illinois 
Natural History Survey (W. E. LaBerge) ; University of Arkansas (E. P. Rouse); University of Missouri (W. R. Enns); and Los Angeles County Museum of Natural History (E. M. Fisher). R. M. Bohart kindly sent data from other collections examined by him, and H. E. Evans examined specimens of $P$. exclamans at the American Museum of Natural History. I have personally obtained data from collections at Cornell University and the Museum of Comparative Zoology.

This research was supported by NSF grant GB-336 to the University of Michigan Museum of Zoology and a grant from the Committee on Evolutionary Biology at Harvard University.

Howard E. Evans, William G. Eberhard, Janice Matthews and Robert Matthews made helpful criticisms of the manuscript. Kathleen Eickwort kindly made available the pre-publication manuscript of her paper on Polistes exclamans.

\section{REFERENCES}

BoHART, R. M.

1951. Family Vespidae, in C. F. W. Muesebeck, K. V. Krombein, H. K. Townes, editors, Hymenoptera of America North of Mexico, Caskey, D. U.S.D.A. Agriculture Monograph, 2: 875-907.

1955. The behavior of Polistes exclamans. Unpublished Master's Thesis, Baylor University.

EICKWORT, K.

Separation of the castes of Polistes exclamans and notes on its Hamilton, W. D. biology (Hym. Vespidae). Insectes Sociaux. In press.

1964. The genetical evolution of social behavior. II. J. Theoret. Biol. 7: 17-52.

MAYR, E.

1963. Animal Species and Evolution. Belknap Press, Cambridge, Mass. xiv $+797 \mathrm{pp}$.

Porter, C. C.

1963. Some new locality records for the social wasp Polistes exclamans Viereck (Hymenoptera, Vespidae). Ent. News 74(7): 176.

RaU, Phil.

1929. The habitat and dissemination of four species of Polistes wasps. Ecology 10(2): 191-200.

1941. Observations on certain lepidopterous and hymenopterous parasites of Polistes wasps. Ann. Ent. Soc. Amer. 34: 355-366.

1942a. Habitat preferences of the Polistes wasp. Ent. Nerws 53: 293-95.

1942b. The nesting habits of Polistes wasps as a factor in taxonomy. Ann. Ent. Soc. Amer. 35(3): 335-338.

1943. The nesting habits of Mexican social and solitary wasps of the family Vespidae. Ann. Ent. Soc. Amer. 36: 515-536.

Unpublished manuscript. The bionomics of Polistes wasps. 
Rau, Phil and Nellie Rau.

1918. Wasp Studies Afield. Princeton Univ. Press, Princeton, N. J. $\mathrm{xv}+372 \mathrm{pp}$.

WEST, M. J.

1967a. The social biology of polistine wasps. Doctoral Dissertation, University of Michigan, Ann Arbor (University Microfilms, Ann Arbor, Michigan).

1967b. Foundress associations in polistine wasps: dominance hierarchies and the evolution of social behavior. Science 157(3796): 15841585.

WHEELER, W. M.

1922. Social Life Among the Insects. Constable \& Co., Ltd., London. $375 \mathrm{pp}$. 

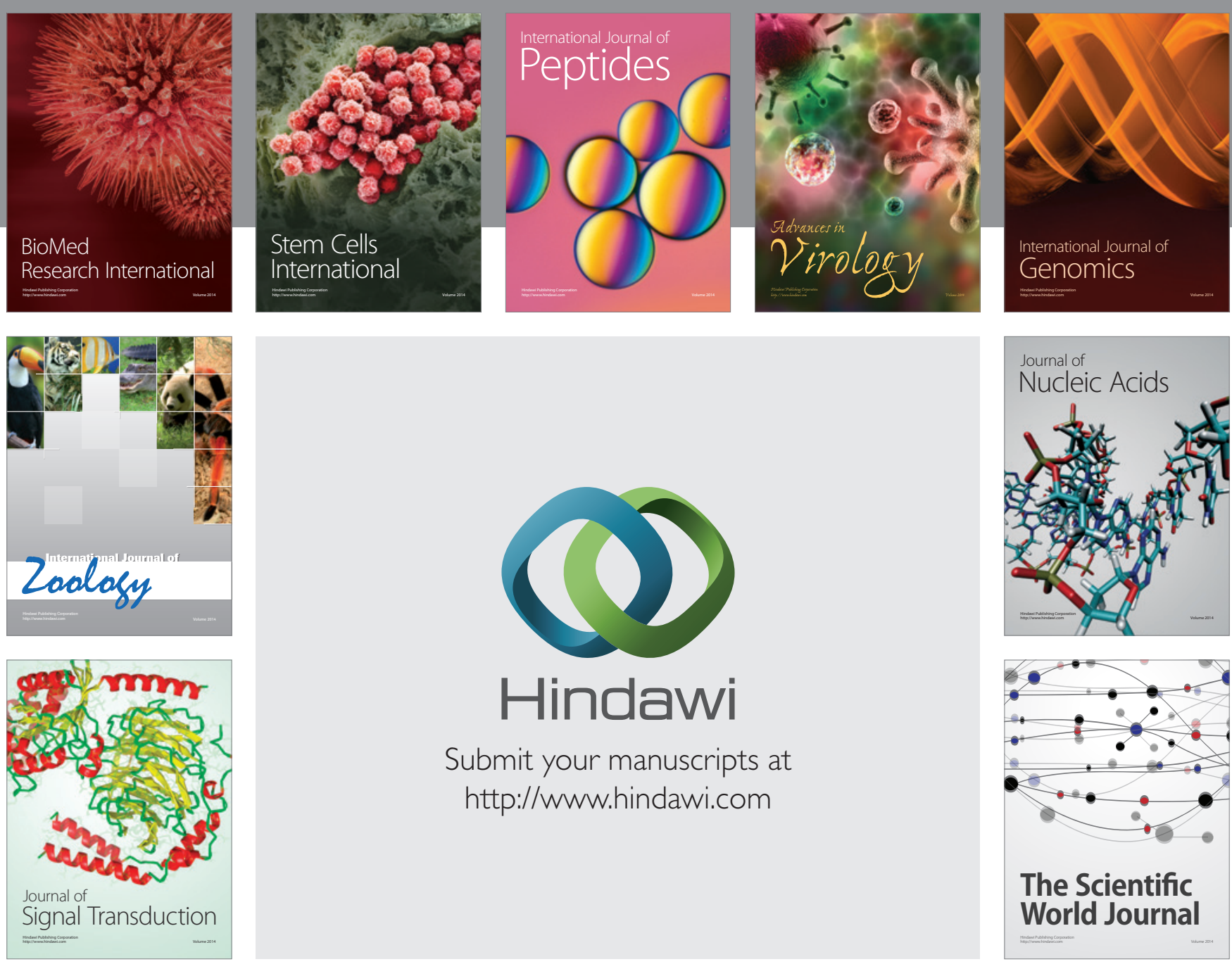

Submit your manuscripts at

http://www.hindawi.com
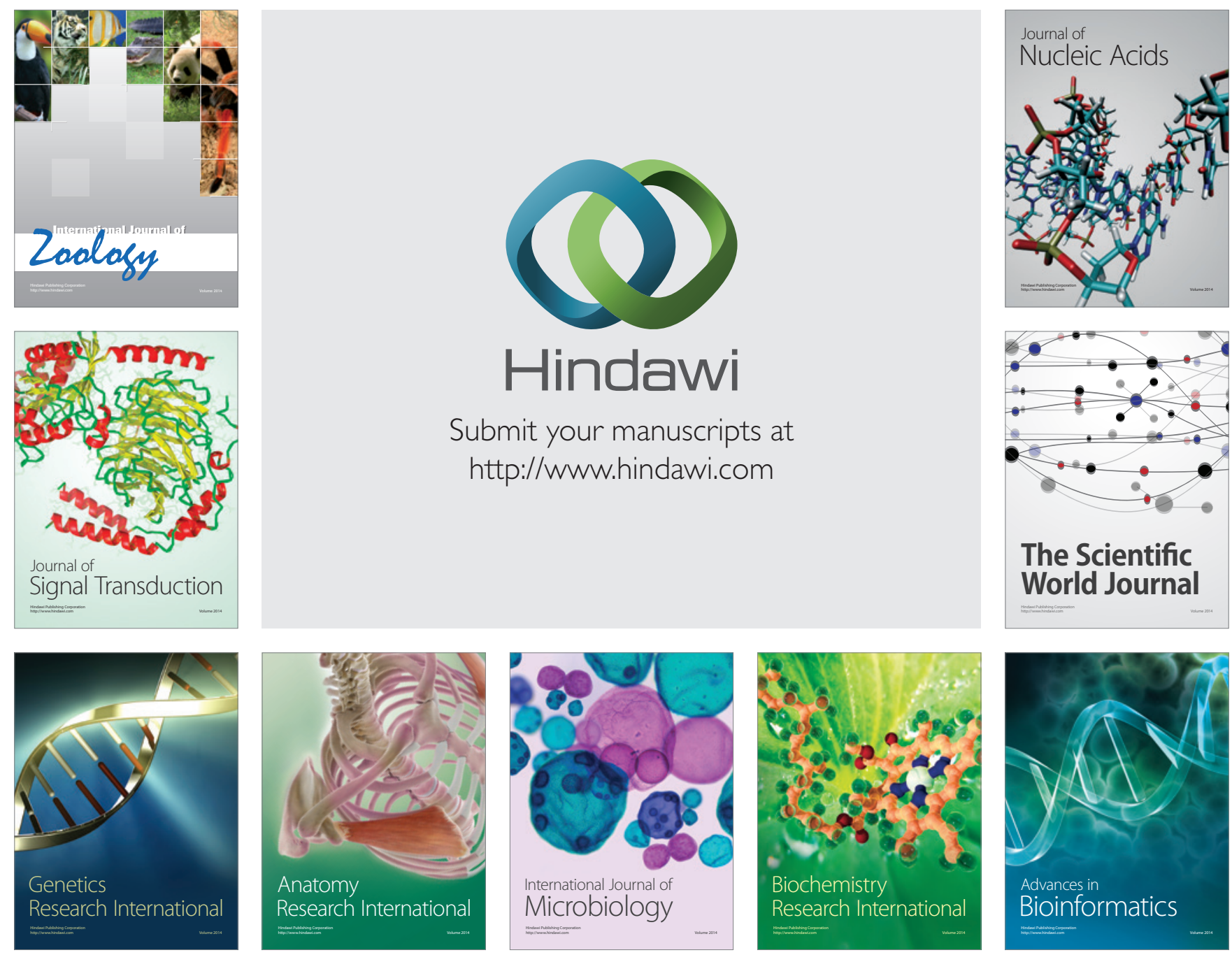

The Scientific World Journal
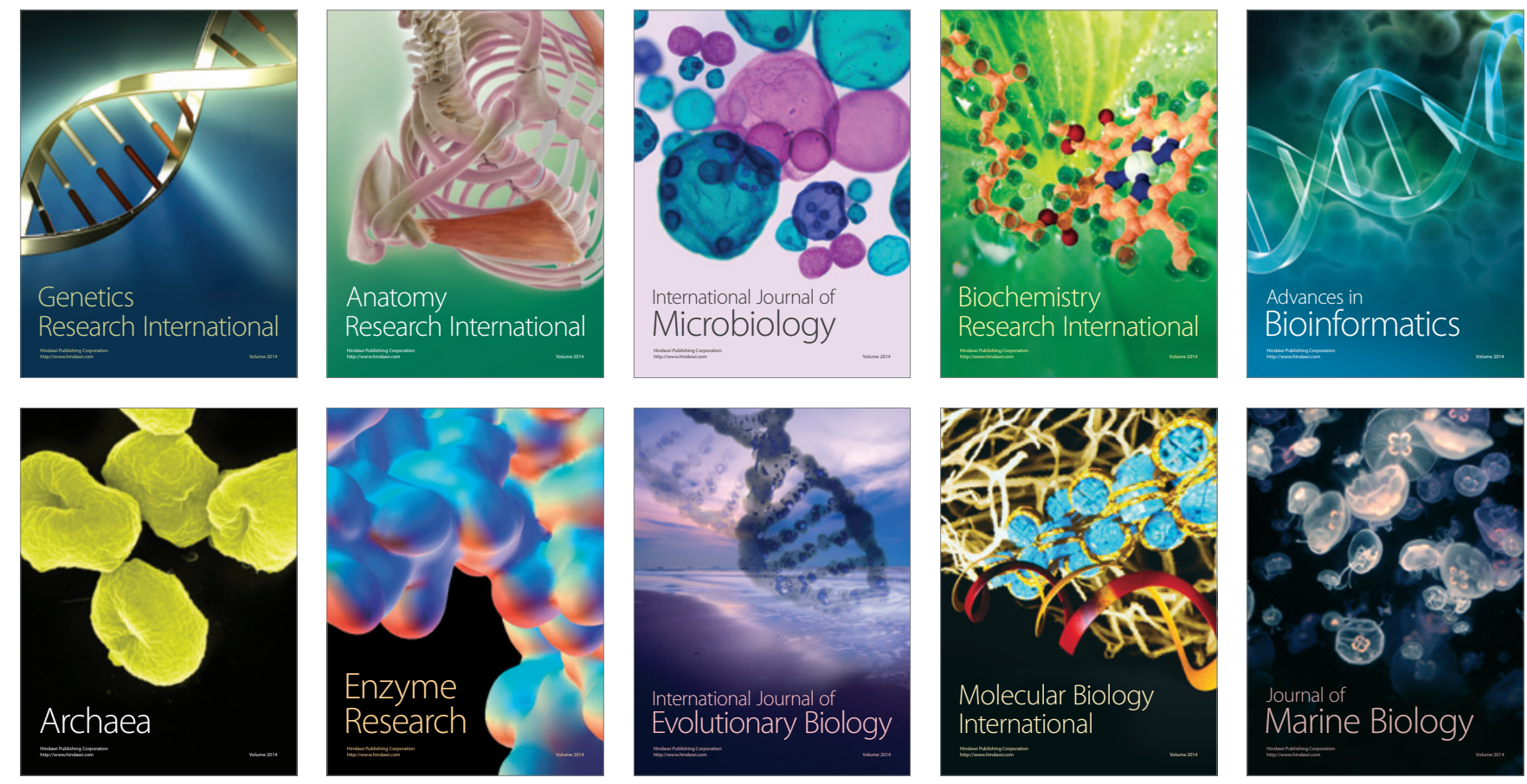